Acta Protozool. (2020) 59: 149-155

www.ejournals.eu/Acta-Protozoologica

doi:10.4467/16890027AP.20.012.13267

PROTOZOOLOGICA

\title{
The First Record of Intestinal Ciliates from the Mountain Zebra (Equus zebra) in South Africa
}

\author{
Olga KORNILOVA ${ }^{\mathrm{a}}$, Klara TSUSHKO ${ }^{\mathrm{b}}$, Ludmila CHISTYAKOVA ${ }^{\mathrm{c}}$ \\ a Department of Zoology, Herzen State Pedagogical University of Russia, St. Petersburg, Russia \\ b Core Facility Centre "Culture Collection of Microorganisms" St. Petersburg State University, St. Petersburg, Russia \\ ${ }^{\mathrm{c}}$ Laboratory of Parasitic Worms and Protistology, Zoological Institute RAS, St. Petersburg, Russia
}

\begin{abstract}
This paper is a first report on species of endosymbiotic ciliates (Litostomatea, Trichostomatia) inhabiting the intestine of zebras in South Africa. Ciliates from Mountain Zebra were investigated for the first time in the world. The wild population of mountain zebras in general and the Cape Mountain Zebra subspecies in particular is low in numbers: this species is included as vulnerable in the IUCN Red List. Approximately 15 species of trichostome ciliates from 9 different genera were found in the samples collected from wild zebras in Western Cape, South Africa. Some of the ciliate species are also common to horses and other equids, while others are unique for zebras. The ciliates of Triplumaria genus common to elephants and rhinoceroses, and the species Blepharosphaera ceratotherii previously described in rhinoceroses were found in equids for the first time.
\end{abstract}

Keywords: Trichostomatia, ciliate, Triplumaria, Equus zebra, mountain zebra.

\section{INTRODUCTION}

Endosymbiotic ciliates from the intestines of zebras have scarcely been investigated in comparison with those in other equids. In 1914, the expedition lead by Russian scientists Valentin Dogiel and Ivan Sokolow collected samples from the digestive tract of different African ungulates in East Africa including one plains zebra (Equus quagga, formerly Equus burchellii Boddaert, 1785) which had been hunted near the Longonot Farm on the Lake Naivasha in Kenya (Dogiel and

Address for correspondence: Olga Kornilova, Faculty of Biology, A.Herzen State Pedagogical University of Russia, 48 Moika River Emb., 191186, St. Petersburg, Russia; E-mail: 3kornilova@gmail. com
Sokolow 1916). The Russian scientists planned to collect more samples in Africa; however, the beginning of the First World War forced their urgent return to Russia. Later Valentin Dogiel concentrated on the investigation of rumen ciliates from African artiodactyls and described some new species, but he gave samples from zebra to his colleague Alexander Strelkow, who described some new ciliate species found in different parts of the animal's intestines (Strelkow 1931). Since then, for nearly 90 years no more ciliates from wild zebras have been investigated. The only samples of feces were collected from Chapman's and Grévy's zebras kept in captivity in zoos and biosphere reserves in Europe and Asia (Kornilova 2003). In 2019 one of the authors visited South Africa, Western Cape and had an opportunity to collect some fecal samples from zebras in nature. 
This paper is a first report on the species of endosymbiotic ciliates (Litostomatea, Trichostomatia) inhabiting the intestines of the wild mountain zebra (Equus zebra Linnaeus, 1758) of South Africa.

\section{MATERIALS AND METHODS}

The samples of feces were collected from wild cape mountain zebras (Equus zebra zebra) at Gourikwa Private Nature Reserve (S 34 $22.992^{\prime}$ E $21^{\circ} 45.311^{\prime}$ ) in South Africa, Western Cape, in July 2019. The small herd of 3 zebras was found, it consisted of one male (№1) and two females: an adult one (№2) and its offspring (№3). Their grazing was carefully observed in order to obtain fresh samples of feces from all three different zebras. Taken samples were immediately fixed within five minutes after defecation to prevent the destruction of ciliates. However, the feces, even though they were fresh, were severely dehydrated, which generally means that a low number of ciliates will be found in such samples. The samples were fixed in $96 \%$ ethanol, as, unfortunately, the transportation and travel conditions made the use of formalin solutions impossible. Ciliates may change their shape when stored in highly concentrated ethanol, which may cause some problems with their identification later. Upon arrival at the laboratory we re-fixed some part of samples in a formalin solution (4\% aq.) in hope to rehydrate ciliates and restore their shape. Although our observations did not confirm reliable the supposition that refixing samples from ethanol to formaldehyde solution would enable to restore the shape of ciliates, but refixed samples became more convenient for contacting with water-based dye solutions, and further investigations.

The ciliates were stained with methyl green $1 \%$ solution in $1 \%$ acetic acid, and with Lugol's iodine. We used an optical microscope MBI-11 and an optical inverted microscope Altami Invert-3 with ocular micrometer in the preliminary examination of the samples. Ciliates were observed and photographed on glass object slides using a Leica DM 2500 equipped with differential interference contrast (DIC). In some cases this method allows to obtain more information about the ciliature, the cortical structures, and other morphological features of ciliates without any additional treatment of samples.

Ciliate species and genera were identified and classified mainly based on the descriptions provided by Gassovsky (1919), Hsiung (1930), Hoare (1937), Strelkow (1931, 1939), Latteur et al. (1970), Wolska (1971, 1985), Timoshenko and Imai (1995), Van Hoven et al. (1998), Lynn (2008), Ito et al. (2008, 2010, 2011), Gürelli and Ito (2014).

For microphotography, we used the digital cameras Leica DFC495 (8.0MP) and Nikon Coolpix 4500 (4.0MP). In addition, "ImageJ" software was used for the first time to reconstruct images of ciliates from several (usually 3 or 4 ) photos made at different levels of the same cell. When observing thick cells, common to many trichostomatids, it may be problematic to present all structural features of the species in one photo. We suggest that this method of reconstruction enables the researcher to demonstrate a comprehensive image of a ciliate, including several important taxonomic characters, in one picture. The total number of ciliates was counted on slides in a fixed volume of liquid. Due to a very low number of ciliates in the samples we decided to present the results in the following way: + single specimen, ++ approximately 10 cells per $\mathrm{ml},+++$ considerably more than 10 cells per $\mathrm{ml}$. This kind of presentation should also make it easier to compare our data with other information about the ciliate fauna in zebras. We did not calculate the prevalence and relative abundance of different ciliate species because we were able to consider the samples from two zebras only.

\section{RESULTS AND DISCUSSION}

As a result of our investigations we found 15 species of ciliates belonging to 9 genera, 4 families of Trichostomatia, Litostomatea (Table 1, Fig. 1). The most abundant and diverse composition of ciliates was found in the fecal samples from the male zebra (№ 1) and the young female (№ 3). The feces of the older female zebra (№ 2) were the most dehydrated and contained the smallest number of ciliates; we found only several cells in the sample № 2, and all of them were so severely deformed that we could not define their taxonomic position. Thus, we could compare and analyse the information about the ciliate fauna only from two zebras - the male and the younger female. Unfortunately, we could not find ciliates with clearly distinguishable contractile vacuoles in either of the samples. This may have been the result of high dehydration of the content in the distal part of a zebra's digestive tract. Consequently, it was impossible to identify some species for which the number and the position of contractile vacuoles are the specific features. For such ciliates we could identify only their genus.

The species composition of ciliates from the intestines of wild Cape mountain zebras was quite different from that of other zebra species. For instance, not a single allantosomatid was detected in the studied samples. We found various representatives of the family Buetschliidae Poche 1913. Small ciliates belonging to different species of the genus Bundleia were the most common in the samples (Fig. $1 \mathrm{i}-1$ ). Such ciliates as Alloiozona trizona, Holophryoides ovalis, H. macrotricha, Blepharoprosthium pireum, which are quite usual for different other hosts, were found in zebras for the first time (Fig. 1 a, b, d. g).

We found two different Blepharosphaera species: one of them, $B$. intestinalis, is common to equids, another one, B. ceratotherii, had been found only once before in the intestines of the white rhinoceros (Van Hoven et al. 1998). Thus, B. ceratotherii is recorded from equids for the first time. These two species of Blepharosphaera are distinguishable according to their dimen- 
Ciliates from Mountain Zebra

151

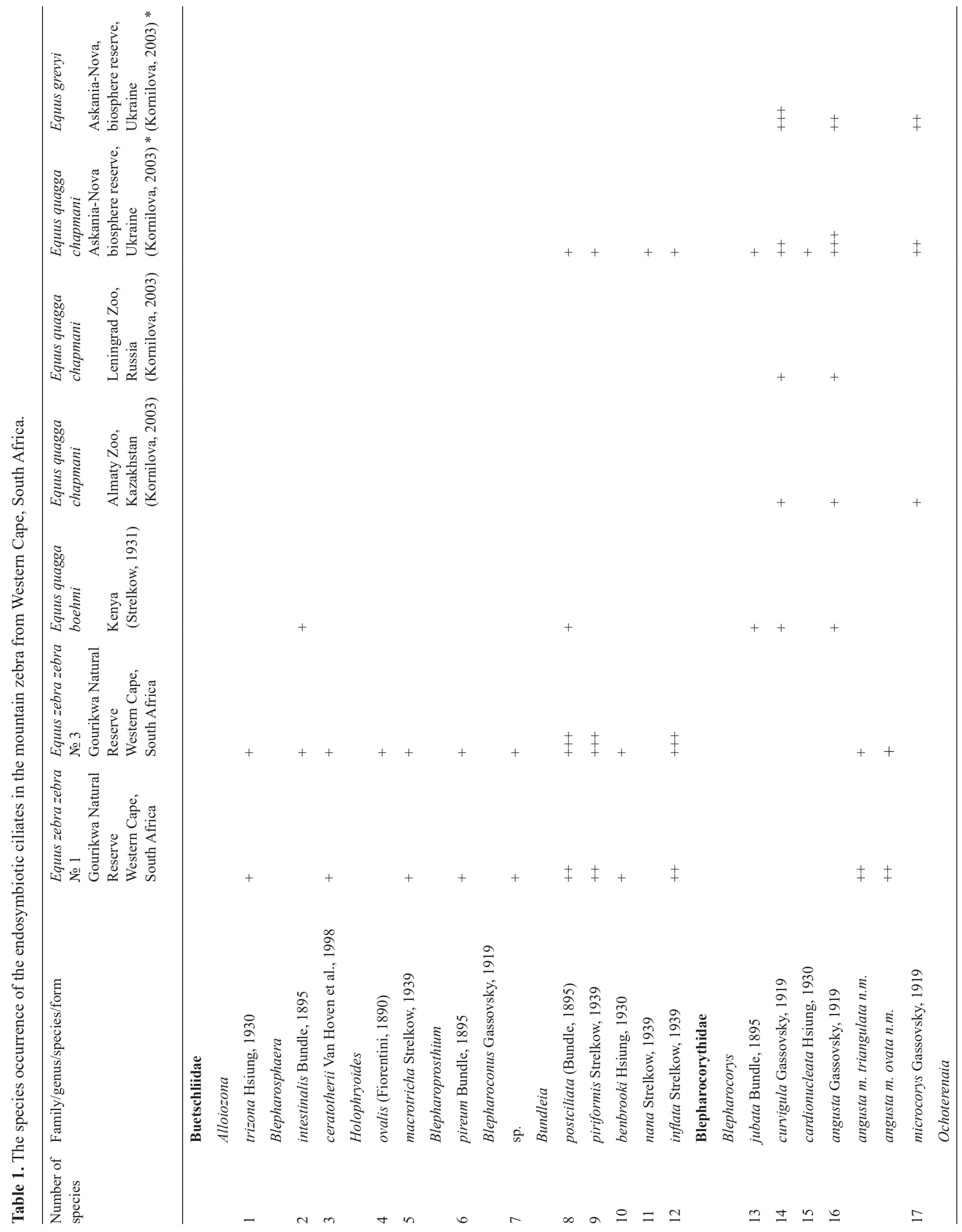


152 O. Kornilova et al.

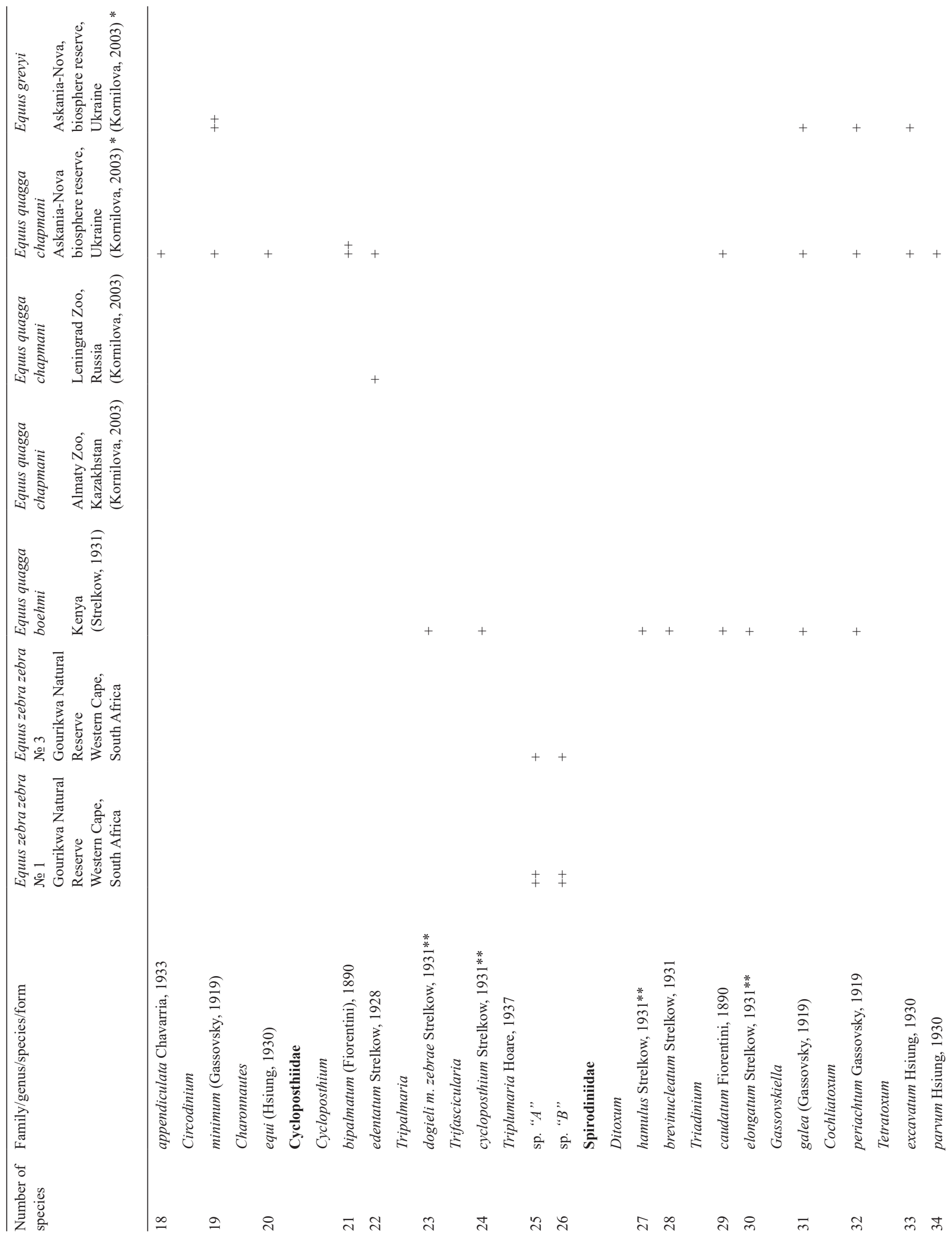




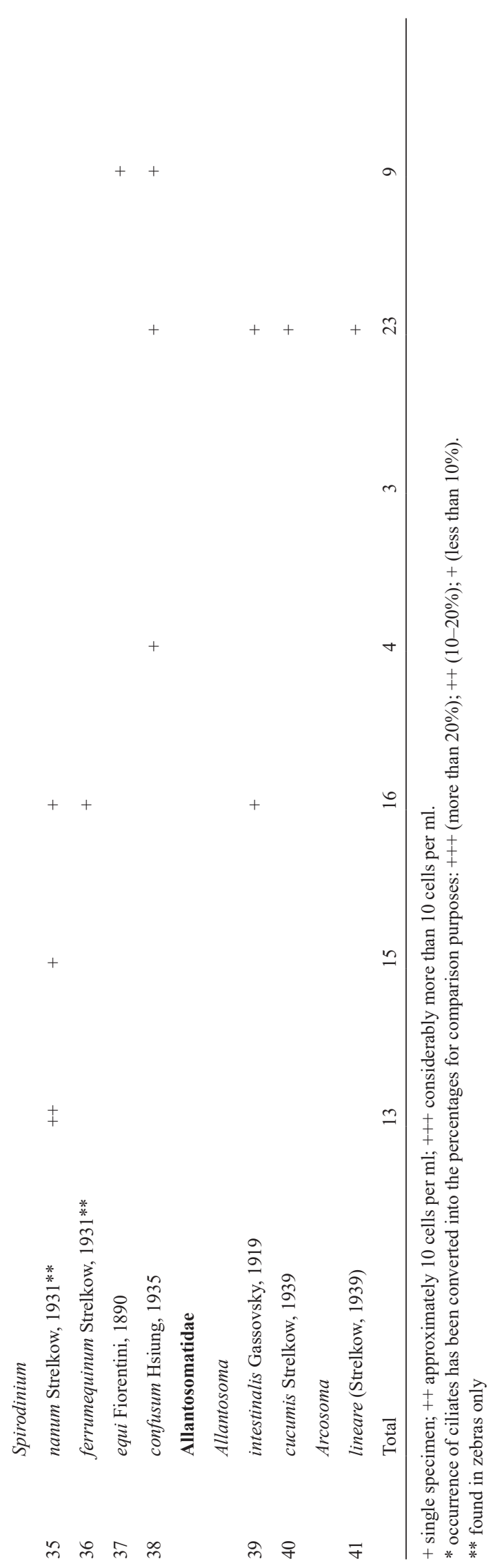

sions: the length of the body $B$. ceratotherii is $27-40$ $\mu \mathrm{m}$, while the length of $B$. intestinalis is $48-80 \mu \mathrm{m}$.

One of the ciliate species may belong to the genus Blepharoconus, as its features correspond to the description of genus by Gassovsky (1919). However, the shape of this ciliate is changeable and we could not clearly identify its species because of the low number of cells in the samples. Different representatives of the genus Blepharoconus inhabit the intestines of horses, elephants, and rhinoceroses.

Only one species of the family Blepharocorythidae Hsiung, 1929 Blepharocorys angusta was found in all the zebras which were investigated (Fig. 1 e, f). All individuals of that ciliate species corresponded to its description, but some of them were more elongated (the length/width ratio 3.2-3.8) and rounded at the ends, while others were shorter (the length/width ratio 2.0 $2.5)$ and had triangular shape of the cell. In our opinion, there were two different morphotypes of $B$. angusta, and we named them $B$. angusta $m$. ovata and $B$. angusta $m$. triangulata respectively. This species is widespread in the world; however, it is for the first time that two different morphotypes of the species were found in the same host. It should also be noted that we did not find any Blepharocorys curvigula, which are supposed to be the most common species of ciliates in zebras, according to previously available data.

The species Spirodinium nanum (fam. Spirodiniidae Strelkow, 1939) was recorded for the first time after the description by Strelkow in 1931 (Fig. 1 m). Its representation was quite numerous in the samples from the male zebra, and single cells were also found in the samples from the young female zebra.

Perhaps the most interesting finding was that of two species of the genus Triplumaria (fam. Cycloposthiidae Poche, 1913), discovered in equids for the first time. Representatives of the genus were previously described from the intestines of rhinoceroses and elephants and have never been observed in the intestines of equids. The transfer of the ciliates may have occured while the same pastures and watering places were used by their hosts; nevertheless, the list of ciliate species and genera which are common to equids, rhinoceroses, and elephants is short in spite of the same habitats of the hosts with the same hindgut fermentation.

The two Triplumaria species from mountain zebras were differentiated by their dimensions, the shape of the macronucleus, and the structure of the distal part of the cell (Fig. $3 \mathrm{n}, \mathrm{o}$ ). The body size of Triplumaria sp. "A": 65-80 $\mu \mathrm{m}$ (length) x 30-40 $\mu \mathrm{m}$ (dorso-ventral 
154 O. Kornilova et al.
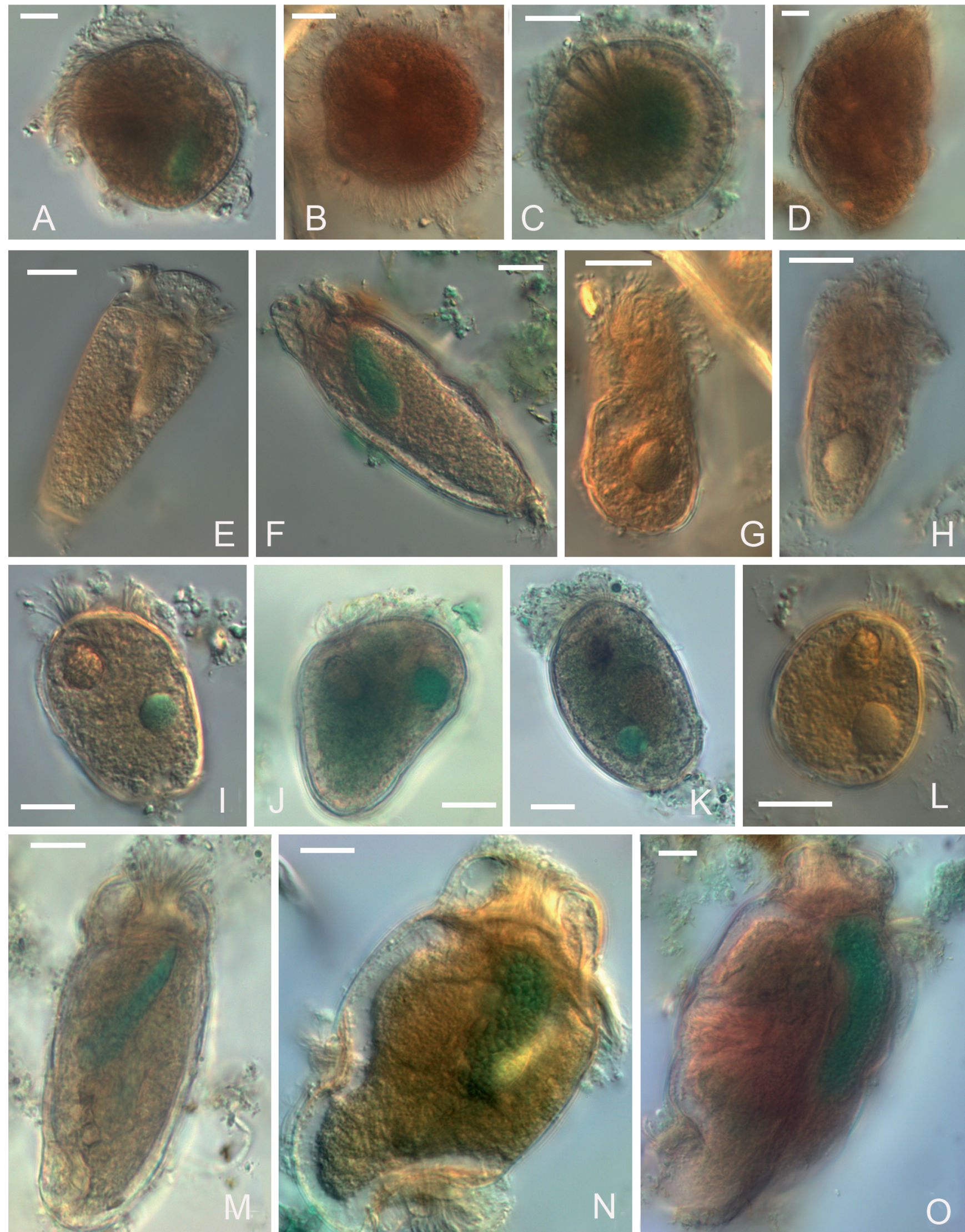
“width"), Triplumaria sp. "B": 80-120 $\mu \mathrm{m}$ x 40-70 $\mu \mathrm{m}$. The posterior end of Triplumaria sp. "B" was oval, and the posterior end of Triplumaria sp. "A" resembled a hook, often pointed at the end. In both species macronuclei were found at the anterior part of the cell, just near the oral ciliature. The macronucleus in Triplumaria sp. "B" was sausage-like, and in Triplumaria sp. "A" it had a noticeable thickening (a "bulb") at its anterior end. Unfortunately we could not define these ciliates to the species level for the reasons discussed above.

To conclude, the first records of endosymbiotic ciliates from the digestive tract of mountain zebras showed an unusual composition of species including species common to horses, zebras, elephants and rhinoceroses. The list of ciliate species inhabiting the intestines of zebras expanded from 31 species (Strelkow 1931; Kornilova 2003) to 41 as a result of our research. The first and successful investigation of endosymbiotic ciliates in zebras from South Africa showed good opportunities and prospects for future researches.

Acknowledgements. We would like to express our gratitude to the owners of the Gourikwa Private Nature Reserve, Western Cape, South Africa for giving us permission to conduct our research, and to Theresa Assad for the assistance with sample collection.

Funding. The research was partly funded by Budgetary Program AAAA-A19-119020690109-2 (Zoological Institute RAS).

\section{REFERENCES}

Dogiel V. A, Sokolow I. I. (1916) The route and brief description of the travel. In: Scientific results of the Zoological Expedition to British East Africa and Uganda made by Prof. V. Dogiel and I. Sokolow in the year 1914: 1-91

Gassovsky G. N. (1919) On the microfauna of the intestine of the horse. Travaux de la Seciété des Naturalistes de Pétrograd 49: 20-37, 65-69

Gürelli G., Ito A. (2014) Intestinal ciliated protozoa of the Asian elephant Elephas maximus Linnaeus, 1758 with the description of Triplumaria izmirae n. sp. Eur. J. Protistol. 50: 25-32
Hoare C. A. (1937) A new cycloposthiid ciliate (Triplumaria hamertoni gen. n., sp. n.) parasitic in the Indian rhinoceros. Parasitology 29: 559-569

Hsiung T. S. (1930) A monograph on the protozoan fauna of the large intestine of the horse. Iowa State College Journal of Science 4: 359-423

Ito A., Van Hoven W., Miyazaki Y., Imai S. (2008) Two new entodiniomorphid Triplumaria ciliates from the intestine of the wild African white rhinoceros. Eur. J. Protistol. 44: 149-158

Ito A., Honma H., Gürelli G., Göçmen B., Mishima T., Nakai Y., Imai S. (2010) Redescription of Triplumaria selenica (Ciliophora, Entodiniomorphida) and its phylogenetic position based on the infraciliary bands and 18SSU rRNA gene sequence. Eur. J. Protistol. 46: 180-188

Ito A., Mishima T., Nataami K., Ike K., Imai S. (2011) Infraciliature of eight Triplumaria species (Ciliophora, Entodiniomorphida) from Asian elephants with the description of six new species. Eur. J. Protistol. 47: 256-273

Kornilova O. A. (2003) The fauna of ciliates from the intestine of Asiatic wild ass (kulan). St. Petersburg: TESSA. 216 pp.

Latteur B., Tuffrau M., Wespes G. (1970) Triplumaria selenica n. sp., Cilie Spirotriche du colon de l'elephant d'Afrique. Protistologica 6: 319-330

Lynn D. H. (2008) The ciliated protozoa. In: Characterization, Classification, and Guide to the Literature, 3rd ed. Springer Science+Business Media B.V. 605 pp.

Strelkow A. (1931) Über die Fauna des Colons beim Zebra. Zool. Anz. 94: $37-54$

Strelkow A. (1939) Parasitical Infusoria from the intestine of Ungulata belonging to the family Equidae. Uchenye Zapiski, LGPI im. Gertsena 17: 1-262

Timoshenko O., Imai S. (1995) Eleven new ciliate species of the genus Triplumaria (Ciliophora, Entodiniomorphida) from Asian elephant, Elephas maximus and African elephant, Loxodonta africana. J. Protozool. Res. 5: 157-175

Van Hoven W., Gilchrist F. M, Liebenberg H., Van der Merwe C. F. (1998) Three new species of ciliated protozoa from the hindgut of both white and black wild African rhinoceroses. Ond. J. Vet. Res. 65: 87-95

Wolska M. (1971) Studies on the family Blepharocorythidae Hsiung. V. A review of genera and species. Acta Protozool. 9: 23-43

Wolska M. (1985) A study of the genus Spirodinium Fiorentini, Ciliata, Entodiniomorphida. Acta Protozool. 24: 1-11

Received on $13^{\text {th }}$ October, 2020; revised on $27^{\text {th }}$ November, 2020; accepted on $2^{\text {nd }}$ December, 2020

Fig. 1. (A-O) Endosymbiotic ciliates from mountain zebra of South Africa: A - Alloiozona trizona, B - Holophryoides macrotricha, $\mathrm{C}$ - Blepharosphaera ceratotherii, D - Holophryoides ovalis, E - Blepharocorys angusta m. triangulata, F - Blepharocorys angusta m. ovata, $\mathrm{G}$ - Blepharoprosthium pireum, H - Blepharoconus sp., I - Bundleia postciliata, J - Bundleia piriformis, $\mathrm{K}$ - Bundleia inflata, $\mathrm{L}$ - Bundleia benbrooki. M - Spirodinium nanum, N - Triplumaria sp. “A”, O - Triplumaria sp. “B”. Differential interference contrast, N, $\mathrm{O}$ - reconstruction from 3 images. Scale bars: $10 \mu \mathrm{m}$. 